\title{
Role of Vasopressin Injection Intramyometrial in Decreasing Blood Loss During Abdominal Myomectomy : A Randomized Controlled Trial
}

Article

\author{
Alaa Elgendy, Ahmed Ahmed, Amro Elhoussieny, Haithem Gad \\ Department of Obstetrics and Gynecology, Faculty of Medicine, Ain-Shams University, Cairo
}

\begin{abstract}
Background: Abdominal myomectomy is a major operation. Massive blood loss is the most serious complication which should be taken in consideration to decrease morbidity and mortality. There are several modalities to decrease blood loss approached in different studies as preoperative GnRh, uterine artery tourniquet, tranexamic acid, vasopressin ...etc.

Aim: The aim of the study was to assess the role of vasopressin injection intramyometrial in decreasing blood loss during abdominal myomectomy. The study was done on women who were scheduled for abdominal myomectomy in Ain-Shams University Maternity Hospital.

Materials and Methods: This study is a randomized clinical trial study which was conducted at Ain-Shams University Maternity Hospital on 60 women with uterine fibroid admitted for abdominal myomectomy to detect if vasopressin injection intramyometrial had a role in decreasing blood loss versus placebo or not.

Results: The end results showed that that the mean of blood loss was $826.67 \mathrm{cc}$ with standard deviation 185.94 and $115.53 \mathrm{cc}$ with standard deviation 23.17 at control and vasopressin group respectively with $p$-value $<0.001$ which indicates that there a highly significant difference in blood loss between two groups. The mean reduction in hemoglobin was 1.38 and $0.08 \mathrm{~g} / \mathrm{dl}$ in control and vasopressin group respectively with $p$-value $<0.002$ which showed that there was a significant difference between them, only $30 \%$ of the control group need blood transfusion and no need for transfusion in the vasopressin group.

Conclusion:Intramyometrial vasopressin injection during abdominal myomectomy may effectively decreases the blood loss, need for blood transfusion and it causes less reduction in haemoglobin and haematocrit. Thereby it seems to be an effective method without having any risk of ischemic damage to the uterus.
\end{abstract}

Key Words: Blood loss during abdominal myomectomy, vasopressin injection intramyometrial

Received: 23 September 2019, Accepted: 23 September 2019

Corresponding Author: Alaa Elgendy, Department of Obstetrics and Gynecology, Faculty of Medicine, Ain-Shams University, Cairo Tel.: 01005209309, E-mail: alaagandy@yandex.com

ISSN: 2090-7265, February 2021, Vol.11, No. 1

\section{INTRODUCTION}

Uterine myomata are the most frequent tumours of the female genital tract affecting $20-50 \%$ of all women, with an increased incidence in the later years of a woman's reproductive life ${ }^{[1]}$. Myoma is mostly asymptomatic. Size and location are the main factors that determine if a myoma leads to symptoms and problems. Important symptoms include abnormal uterine bleeding, abdominal discomfort, bloating, painful defecation, backache, urinary frequency or retention and infertility. It is associated with impairment of Health-Related Quality of Life (HRQOL) ${ }^{[2]}$.

Patients have multiple options in the management of uterine myomas including observation, medical therapy, uterine artery embolization, high intensity focused ultrasound ablation and as well as surgical methods like myomectomy and hysterectomy. Surgical removal is necessary when the myoma is symptomatic and resistant to medical management or interferes with reproduction.
Although uterine artery embolization is now an effective way for managing symptomatic uterine myomas but its effect on future conception remains unclear ${ }^{[3]}$.

There are various pharmacological and nonpharmacological methods have been tested to control haemorrhage during myomectomy. At present, there is moderate-quality evidence that misoprostol may reduce bleeding during myomectomy, and low-quality evidence that bupivacaine plus epinephrine, tranexamic acid, gelatin-thrombin matrix, ascorbic acid, dinoprostone, loop ligation, fibrin sealant patches, peri-cervical tourniquet, or tourniquet tied around both cervix and infundibulopelvic ligaments may reduce bleeding during myomectomy. There is no evidence that oxytocin, morcellation or temporary clipping of the uterine artery reduce blood $\operatorname{loss}^{[4]}$.

Intra-myometrial vasopressin injection during myomectomy operation may effectively decrease the intraoperative blood loss, need for blood transfusion, and 
causes less reduction in haemoglobin and haematocrit in postoperative period. It also eliminates the risk of unwanted irreversible ischemic damage to the uterus and thrombo-embolic events of mechanical methods ${ }^{[5]}$. On the other hand, and because it is a potent systemic vasoconstrictor, vasopressin may cause cardiac arrest and bradycardia $^{[6]}$. It has a plasma half-life of 10-20 minutes. Care should be taken to infiltrate a dilute solution with hemodynamic monitoring and to avoid unwanted surges in blood pressure. The anti-diuretic activity of vasopressin can last for two to eight hours.

This can be easily reversed with an intravenous diuretic like Frusemide. Vasopressin is a uterotonic in the nonpregnant uterus. It is secreted from the posterior pituitary gland.It regulates plasma volume, blood pressure, and osmolality. It causes vasoconstriction by acting through the vasopressin (V1) receptor ${ }^{[7]}$.

Vasopressin also stimulates uterine contractions by acting through myometrial (V1a) receptors. Vasopressin receptors are present in the myometrium of both pregnant and nonpregnant women. Because vasopressin activates V2 receptors on endothelial cells causing a release of endothelial Von Willebr factor, it enhances platelet aggregation and therefore may increase the risk of thrombosis ${ }^{[8]}$

Terlipressin (triglycyl-lysine vasopressin) became popular in the early 1990s because it has a prolonged duration of action. It is a prodrug and is converted to the lysine vasopressin in the circulation after the $\mathrm{N}$-triglycyl residue is cleaved by endothelial peptidases. This results in a 'slow release' of the vasoactive lysine vasopressin ${ }^{[9]}$. The effect half-life of terlipressin is $6 \mathrm{~h}$. It causes a prolonged reduction of portal venous pressure (mean $103 \mathrm{~min})^{[10]}$. The elimination half-life of terlipressin is $50 \mathrm{~min}$.

\section{AIM OF THE WORK}

The aim of the study was to assess the role of vasopressin injection intramyometrial in decreasing blood loss during abdominal myomectomy. The study was done on women who were scheduled for abdominal myomectomy in Ain-Shams University Maternity Hospital.

\section{PATIENTS AND METHODS}

This study is a randomized clinical trial study which was conducted at Ain Shams University Maternity Hospital from February 2018 to January 2019 on 60 women with uterine fibroid admitted for abdominal myomectomy to detect if vasopressin injection intramyometrial had a role in decreasing blood loss versus placebo or not.

The ethical committee at Ain-Shams University had approved the study protocol.

Selection criteria: Women who were eligible for the study $(n=60)$ were randomized equally into; study group (group V) including 30 women who were injected with vasopressin intramyometrial as well as control group (group C) including 30 women who were injected with $200 \mathrm{ml}$ saline intramyometrial.

Inclusion Criteria: Women with symptomatic uterine fibroid aged 20-40 years old and desire future pregnancy and not responding to medical treatment: The location of a fibroid, and not its size, was the key factor regarding impact on fertility (Pritts et al., 2009). Leiomyomas that distort the uterine cavity (submucosal or intramural with an intracavitary component) result in difficulty conceiving a pregnancy and an increased risk of miscarriage.

\section{Hysteroscopic or laparoscopic myomectomy was not feasible as:}

a-Any medical conditions that could worse with abdominal distension and a Trendelenburgh position for a prolonged period.

b-Diffuse leiomyomata.

c-Uterine size more than sixteen weeks gestation.

Number of myomas not exceeding five and staging of myoma from (2 to 6) according to FIGO staging ${ }^{[11]}$. Both groups are also matching regarding age, body mass index, parity and preoperative $\mathrm{Hb}$ level.

\section{Exclusion Criteria:}

1. Women who had completed childbearing and who desired hysterectomy.

2. Any medical condition that was not suitable for anesthesia or prolonged surgery.

3 . Those with body mass index $(\mathrm{BMI})>35$ were excluded to avoid its confounding effect on duration of surgery and possibly an increased amount of bleeding caused by difficult surgery.

4. Pregnancy.

5. Leiomyomata located in the region of the uterine vessels or broad ligament or cervical were sometimes difficult to remove without performing a hysterectomy.

6. Excision of very large leiomyomata in relation to uterine size that constitute the entire anterior or posterior wall of the uterus could leave defects so large that closure was prohibited.

7. History of adverse reaction or allergy to vasopressin, and active cardiovascular or pulmonary disease that would indicate a contradiction to use of vasopressin.

8 . Women with malignancy proved by dilatation and curettage (D\&C) biopsy or suspected by imaging.

9. Myomas accessible for hysteroscopic or laparoscopic myomectomy

10. Prolonged QT interval.

11. Medications that interact with vasopressin as class $1 \mathrm{~A}$ and III antiarrhythmics, erythromycin and tricyclic antidepressants or medications that could cause hypokalaemia (e.g. some diuretics). 


\section{Methods:}

All patients enrolled in this study was subjected to the following:

1. Written consent: was obtained from the women on whom the study was performed and they were informed about the objectives of the study.

2. Full history taking:

-Personal history: name, age, marital status, parity, smoking.

-Menstrual history: menarche, amount, associated dysmenorrhea, regularity, LMP.

-Complaint and present history: bleeding, abdominal pain, abdominal swelling, sense of heaviness, GIT symptoms, urinary symptoms, subfertility.

-History of current illness or medications.

-Obstetric history

-Contraceptive history

-Past history of: fibroids, any abdominal or uterine surgeries.

-Family history of fibroids.

General examination: vital signs; pulse, blood pressure, temperature, respiratory rate and body mass index.

-Abdominal examination: Inspection, Palpation.

-Vaginal examination: uterus site, size, mobility, associated pathology.

-Ultrasound examination: fibroid site, size, number.

-Preoperative blood tests: CBC, RBS, SGOT, SGPT, UREA, CREAT, PTT, APTT, INR, ECG.

\section{Allocation and concealment:}

Randomization was performed by a simple randomization method using sealed envelopes, half of which contained notes labelled as (study group V) and the other half was labelled as (control group C). Eligible women were asked to choose one of these envelopes to determine the group to which she would be allocated. The study group received an explanation of the study. This meant that women enrolled in the study and the clinical care teams would not be blinded to the intervention and would be aware of vasopressin administration.

\section{Procedure:}

During myomectomy the following things were noted as; number of myomas removed, weight of the removed myomas, operative time, intraoperative blood loss. Postoperative parameters included haemoglobin and haematocrit values (on the other day), blood transfusion requirement in the postoperative period. Reduction in haemoglobin and haematocrit values was calculated from the differences in the preoperative and postoperative haemoglobin and haematocrit values, the weight of towels pre and post-operative and amount of blood loss in suction apparatus and drain. Any complications during operation or post-operative were recorded. All operations were performed by same surgical unit involving the senior most consultants.

\section{Operative details:}

Before skin incision, all women received prophylactic antibiotic in the form of ceftriaxone $1 \mathrm{~g}$ intravenously (Cairo Co, Egypt). The operations were performed as standard through pfannensteil incision by one or more of the authors to ensure consistency of study procedures. Patients received general or regional anesthesia.

After skin incision, the subcutaneous fat and abdominal fascia were opened crosswise, and the rectus muscle was separated on the midline. The parietal peritoneum was opened longitudinally to reach the pelvic cavity. Subsequently the intestine was packed. Uterus was inspected for number, location, and shape of myomas, and other pelvic organs were inspected for associated pathology.

In the study group, terlipressin (Glypressin, Ferring, Egypt) was diluted with saline as 1 unit of it for every 200 $\mathrm{ml}$ of saline. The maximum used dose was $1 \mathrm{unit} / 200 \mathrm{ml}$ saline.

Care must be taken to ensure the terlipressin was not injected intravascularly. The anesthesiologist was informed prior to the injection of the solution to ensure proper monitoring was being conducted.The amount of diluted vasopressin varied according to the number and size of myomas. Average amount injected at each myoma was $40 \mathrm{cc}$.the amount injected also depended upon the size of each myoma and also on the experience of the surgeon .a 10-ml syringe was inserted between the uterus and the myoma. Needle was inserted to a depth of about $2.5 \mathrm{~cm}$. Single insertion was sufficient in most cases. In some cases, position of the needle was changed once.

Myoma bed was closed by 1 or 2 layers of interrupted vicryl sutures (Vicryl 1-0 polyglactin 910; Egycryl, Taisier CO, Egypt).At the end of the surgery, intraperitoneal suction drain was routinely used in all patients and the volume in the drain bag was measured every 12 hours and on removing the drain. Drain was removed on the second postoperative day unless otherwise indicated.

Number, location and size of myomas were recorded. Myoma size represented the mean size of each myoma. Enucleated myomas were sent for histopathological examination.

The total bleeding was calculated as intraoperative and postoperative blood loss. Intraoperative blood loss was estimated by the investigator by drying up all blood in the surgical field with swabs and then weighing them. The weight of the dry surgical swabs 
(roughly $28 \mathrm{~g}$ for each $30 * 30 \mathrm{~cm}$ abdominal swabs) was measured before use and after being wet or soaked by blood. A highly accurate digital balance was used to measure the weight in grams. The weight difference was translated into the blood loss considering that $1 \mathrm{~g}$ is equal to $1 \mathrm{~mL}$ blood. The quantity of blood loss $(\mathrm{mL})$ equals (weight of the used materials-weight of the materials prior to the surgery) in addition to the blood collected in the suction apparatus after evacuation ${ }^{[12]}$.

Meanwhile, postoperative blood loss was defined as the blood volume found in the suction drain ${ }^{[12]}$. Both study and controlled groups were checked for vital signs (blood pressure, heart rate, and respiratory rate) before and after myomectomy.

CBC was repeated on the next postoperative day to check the drop of $\mathrm{Hb}$ level and hematocrit. Any adverse effects in either group was recorded. The need for blood transfusion either intraoperatively or postoperatively was also recorded. Intraoperative blood transfusion was governed by clinical condition and amount of blood loss.

Postoperative blood transfusion was indicated if hemoglobin $(\mathrm{Hb})$ percentage is $<7 \mathrm{~g} / \mathrm{dL}$ with relevant clinical manifestations. Women were reviewed again 1 week after the operation.

Primary outcome: total blood loss which was calculated by postoperative hemoglobin level drop, transfusion rate, and drainage volume after vasopressin injection intramyometrial during abdominal myomectomy.

Secondary outcome: duration of surgery and postoperative adverse effects such allergy, cardiovascular disorders, pulmonary edema...etc.

\section{STATISTICAL ANALYSIS:}

Data were analyzed using Statistical Program for Social Science (SPSS) version 15.0. Quantitative data were expressed as mean \pm standard deviation (SD). Qualitative data were expressed as frequency and percentage.

\section{The following tests were done:}

1-Independent-samples t-test of significance was used when comparing between two means.

2-Chi-square test: was used when comparing between non-parametric data.

3-Pearson's correlation coefficient (r): test was used for correlating data.

\section{Probability (P-value):}

$-P$-value $<0.05$ was considered significant.

$-P$-value $<0.001$ was considered as highly significant.

$-P$-value $>0.05$ was considered insignificant.

\section{RESULTS}

This study is a randomized clinical trial study which was conducted at Ain-Shams University Maternity Hospital from February 2018 to January 2019 on 60 women with uterine fibroid admitted for abdominal myomectomy to detect if vasopressin injection intramyometrial has a role in decreasing blood loss versus placebo or not. Women eligible for the study $(n=60)$ were divided equally into study and control group. In the study group, terlipressin (Glypressin, Ferring, Egypt) was diluted with saline as 1 unit of it for every $200 \mathrm{ml}$ of saline. In the control group, saline was injected intramyometrial. a lot of issues were taken inconsideration to evaluate the amount of blood loss as site, size, number, volume of removed fibroids ...etc. the most reliable indicator for detection of blood loss was pre and post-operative hemoglobin and hematocrit.

The final results detected that the mean of blood loss was $826.67 \mathrm{cc}$ with standard deviation 185.94 and $115.53 \mathrm{cc}$ with standard deviation 23.17 at control and vasopressin group, respectively, with $p$ value $<0.001$ which indicates that there is highly significant difference in blood loss between two groups. The mean reduction in hemoglobin was 1.38 and $0.08 \mathrm{~g} / \mathrm{dl}$ in control and vasopressin group respectively with $\mathrm{p}$ value 0.002 which showed that there was a significant difference between them. Only $30 \%$ of control group needed blood transfusion and no need for transfusion in the vasopressin group. Only one woman had CVS disorder in vasopressin group inform of transient bradycardia for one min and recurred spontaneously without intervention and no residual side effect after 1 week follow up by ECG.

Table 1 showed no statistical significant difference $(p$-value $>0.05)$ between studied groups as regard age.

Table 2 showed no statistical significant difference $(p$-value $>0.05)$ between studied groups as regard pre-operative $\mathrm{Hb}$. Also, no statistical significant difference $(p$-value $>0.05)$ between studied groups as regard pre-operative Hct.

Table 3 showed highly statistical significant difference ( $p$-value $<0.001)$ between studied groups as regard blood loss. The mean of blood loss was $826.67 \mathrm{cc}$ and $115.53 \mathrm{cc}$ in the control and vasopressin groups, respectively, with 
$p$ value $<0.001$. This means that it is considered highly significant of blood loss between two groups.

Table 4 showed statistically significant difference $(p$-value $<0.05)$ between studied groups as regard postoperative $\mathrm{Hb}$. Also, it showed highly statistical significant difference $(p$-value $<0.001)$ between studied groups as regard post-operative Hct.

Table 5 showed no statistical significant difference
( $p$-value $>0.05)$ between studied groups as regard CVS complications.

Cardiovascular disorder occurred only in one woman of vasopressin group inform of transient bradycardia and then returned to normal rate.

Only one woman had CVS disorder in vasopressin group inform of transient bradycardia for one min and recurred spontaneously without intervention and no residual side effect after 1 week follow up by ECG.

Table 1: Comparison between studied groups as regard age

\begin{tabular}{lcccc}
\hline Variable & groups & $\begin{array}{c}\text { Control group } \\
(\mathrm{N}=30)\end{array}$ & $\begin{array}{c}\text { Vasopressin group } \\
(\mathrm{N}=30)\end{array}$ & $p$-value \\
\hline Age & Mean & 33.40 & 33.37 & 0.9 \\
(years) & $\pm \mathrm{SD}$ & 5.08 & 5.57 & \\
\hline
\end{tabular}

Table 2: Comparison between studied groups as regard pre-operative $\mathrm{Hb}$ and $\mathrm{Hct}$

\begin{tabular}{|c|c|c|c|c|}
\hline Variable & groups & $\begin{array}{l}\text { Control group } \\
\qquad(\mathrm{N}=30)\end{array}$ & $\begin{array}{l}\text { Vasopressin group } \\
\qquad(\mathrm{N}=30)\end{array}$ & $p$-value \\
\hline \multirow{3}{*}{ Pre-operative $\mathrm{Hb}(\mathrm{g} / \mathrm{dl})$} & \multirow{3}{*}{ Mean \pm SD } & 11.13 & 10.87 & \multirow{3}{*}{0.4} \\
\hline & & & & \\
\hline & & 1.06 & 1.10 & \\
\hline \multirow{3}{*}{ Pre-operative Hct (\%) } & \multirow{3}{*}{ Mean \pm SD } & 31.78 & 31.38 & \multirow{3}{*}{0.7} \\
\hline & & & & \\
\hline & & 4.51 & 1.59 & \\
\hline
\end{tabular}

Table 3: Comparison between studied groups as regard blood loss

\begin{tabular}{|c|c|c|c|c|}
\hline Variable & groups & $\begin{array}{l}\text { Control group } \\
(\mathrm{N}=30)\end{array}$ & $\begin{array}{c}\text { Vasopressin group } \\
\qquad(\mathrm{N}=30)\end{array}$ & p-value \\
\hline \multirow{3}{*}{ Blood loss (cc) } & \multirow{3}{*}{ Mean \pm SD } & 826.67 & 115.53 & \multirow{3}{*}{$<0.001^{*}$} \\
\hline & & & & \\
\hline & & 185.94 & 23.17 & \\
\hline
\end{tabular}

*: $p$-value $<0.001$ is considered highly significant

Table 4: Comparison between studied groups as regard post-operative $\mathrm{Hb}$ and Hct

\begin{tabular}{|c|c|c|c|c|}
\hline Variable & groups & $\begin{array}{l}\text { Control group } \\
\qquad(\mathrm{N}=30)\end{array}$ & $\begin{array}{l}\text { Vasopressin group } \\
\qquad(\mathrm{N}=30)\end{array}$ & $p$-value \\
\hline \multirow{3}{*}{ Post-operative $\mathrm{Hb}(\mathrm{g} / \mathrm{dl})$} & \multirow{3}{*}{ Mean \pm SD } & 9.75 & 10.79 & \multirow{3}{*}{$0.001 *$} \\
\hline & & & & \\
\hline & & 0.92 & 1.32 & \\
\hline \multirow{3}{*}{ Post-operative Hct (\%) } & \multirow{3}{*}{ Mean \pm SD } & 26.55 & 28.90 & \multirow{3}{*}{$<0.001 *$} \\
\hline & & & & \\
\hline & & 1.99 & 2.09 & \\
\hline
\end{tabular}

$*$ : $p$-value $<0.05$ is considered significant 
Table 5: Comparison between studied groups as regard CVS complications

\begin{tabular}{lccc}
\hline Variable & groups & $\begin{array}{c}\text { Control group } \\
(\mathrm{N}=30)\end{array}$ & $\begin{array}{c}\text { Vasopressin group } \\
(\mathrm{N}=30)\end{array}$ \\
\hline CVS complications & Nil & $30(100 \%)$ & $29(96.7 \%)$ \\
& Complicated & $0(0 \%)$ & $1(3.3 \%)$ \\
\hline
\end{tabular}

\section{DISCUSSION}

The goal of a myomectomy operation is to remove all the visible and accessible myomas and then reconstruct the uterus. Clinical experience and pooled results of numerous studies suggest that myomectomy can result in considerable blood loss. Haemostasis at the time of surgery is an important issue for the success of the operation and patient's recovery. A lot of studies were done in different manners to detect different interventions to decrease blood loss during abdominal myomectomy. The use of vasopressin was first reported by Dillon in 1962 for abdominal myomectomy.

In this study vasopressin was dissolved in normal saline by 1:200 dilutions. Intramyometrial vasopressin injection reduced the operative time and blood loss for myomectomy operation and the need for blood transfusion.

Randomized trial data show that blood loss during myomectomy with vasopressin is significantly less than with placebo $(299 \mathrm{~mL})$ less Kongnyuy et al. ${ }^{[4]}$ and less than or comparable to use of a uterine artery tourniquet ${ }^{[13]}$.

Randomized single blinded parallel group study were done on 48 patients. All patients were divided into 2 groups, 24 in each group. Vasopressin injected intramyometrial as 20 units in $100 \mathrm{ml}$ of normal saline in a dilution $1: 100$ and the other group tourniquet occluded uterine vessels which was applied immediately before uterine incision and released every $20 \mathrm{~min}$ to avoid ischemic damage of uterus. The blood loss in the tourniquet group was significantly higher $P<0.001$ post operative hemoglobin and hematocrit were lower in tourniquet group than vasopressin group. There was significant fall in hemoglobin and hematocrit in postoperative period in both groups $P<0.001$ but it was more in tourniquet group. Three patients in tourniquet group but two in vasopressin group received one unit of blood transfusion $^{[5]}$.

A randomized placebo controlled trial at University Hospital of the West Indies, Kingston, Jamaica. Twenty women with symptomatic uterine fibroids scheduled for myomectomy who satisfied entry criteria: 10 randomised to the vasopressin group and 10 to the control group. Myomectomy was performed after the intramyometrial injection of either 20 units vasopressin diluted to $20 \mathrm{ml}$ in normal saline or placebo $(20 \mathrm{ml}$ normal saline). The use of vasopressin resulted in median blood loss of $225 \mathrm{ml}$ (range 150-400 ml) compared with $675 \mathrm{ml}$ (range 500-800 $\mathrm{ml}$ ) in the placebo group $(P<0.001)$. Thevasopressingrouphadacorrespondingly lower fall in haemoglobin level (median $1.7 \mathrm{~g} / \mathrm{dl}$ vs $5.3 \mathrm{~g} / \mathrm{dl}, P<0.001$ ) and haematocrit (median $5 \%$ vs $13 \%, P<0.001)$ compared with the controls.

Fifty percent of the placebo group had blood transfusions compared with none in the vasopressin group $(P=0.03)$. There were no significant differences between the groups in intra-operative pulse and blood pressure or post-operative white blood cell counts or temperature ${ }^{[14]}$.

Bradycardia and Cardiac arrest: Hobo et al. ${ }^{[6]}$ have reported a case of bradycardia and cardiac arrest during the procedure of laparoscopic myomectomy in which 11.2 units of vasopressin was injected at adilution of 0.2 units $/ \mathrm{ml}$. Within 2 minutes of the injection the heart rate of patient fell to $58 \mathrm{bpm}$ then to $35 \mathrm{bpm}$ and subsequently cardiac arrest followed within 5 minutes. The vitals were returned to normal range and effective cardiac activity reestablished but as a gloomy outcome, the surgery had to be stopped. The possible causes of these events can be summarized as below: Vasopressin induced increase in blood pressure causes vagal- mediated decrease in heart rate.

Many case reports on bradycardia and cardiac arrest due to vasopressin have shown these 2 causes administration of vasopressin in a dose of more than 5 units $^{[15]}$ and unintentional administration of vasopressin into a blood vessel ${ }^{[16]}$.

\section{CONCLUSION}

Intramyometrial vasopressin injection during abdominal myomectomy may effectively decreases the blood loss, need for blood transfusion and it causes less reduction in haemoglobin and haematocrit. 
Thereby it seems to be an effective method without having any risk of ischemic damage to the uterus.

\section{RECOMMENDATIONS}

According to the results of the study vasopressin intramyometrial may have a role in decreasing blood loss during abdominal myomectomy by using terlipressin (Glypressin, Ferring, Egypt) which was diluted with saline as 1 unit of it for every $200 \mathrm{ml}$ of saline using a 10-ml syringe which was inserted between the uterus and the myoma.

Other studies with different concentrations of diluted vasopressin are recommended to reach to the most effective dosage with the least side effects.

\section{CONFLICT OF INTEREST}

There are no conflicts of interests.

\section{REFERENCES}

1. Wallach EE and Vlahos NF (2004). Uterine myomas: an overview of development, clinical features, and management. Obstet Gynecol; 104(2):393-406.

2. Downes E, Sikirica V, Gilabert-Estelles J, Bolge SC, Dodd SL, Maroulis C, et al. (2010). The burden of uterine fibroids in five European countries. Eur J Obstet Gynecol Reprod Biol; 152(1):96-102.

3. Kitson SJ, Macphail S, Bulmer J(2012). Is pregnancy safe after uterine artery embolisation? BJOG: An Internat J Obstetr Gynaecol; 119(5):519-21

4. Kongnyuy EJ, Wiysonge CS (2014). Interventions to reduce haemorrhage during myomectomy for fibroids.Cochrane Database of Systematic Reviews. (8).

5. Saha MM, Khushboo, Biswas SC, Alam H, Kamilya GS, Mukhopadhyay M, et al. (2016). Assessment of Blood Loss in Abdominal Myomectomy by Intramyometrial Vasopressin Administration Versus Conventional Tourniquet Application. J Clin Diagn Res; 10(5):QC10-3.

6. Hobo R, Netsu S, Koyasu Y, Tsutsumi O (2009). Bradycardia and cardiac arrest caused by intramyometrial injection of vasopressin during a laparoscopically assisted myomectomy. Obstet Gynecol; 113(2 pt 2):484-486.

7. Marieb E (2014). Anatomy \& physiology. Glenview, IL: Pearson Education, Inc. ISBN 978-0-321-858-0.

8. Grant PJ, Tate GM, Davies JA et al. (1986). Intraoperative Activation of CoagulationStimulus to Thrombosis Mediated by Vasopressin. Thrombosis and Haemostasis; 55: 104-7.

9. Rodriguez-Perez F, Groszmann RJ (1992). Pharmacologic treatment of portal hypertension. Gastroenterology Clinics of North America; 21: 15-40.

10. Blei AT, Groszmann RJ, Gusberg R, Conn HO (1980). Comparison of vasopressin and triglycyllysine vasopressin on splanchnic and systemic hemodynamics in dogs. Digestive Disease Science; 25: 688-94.

11. Munro MG, Critchley HO, Broder MS, Fraser IS (2011). FIGO classification system (PALMCOEIN) for causes of abnormal uterine bleeding in non gravid women in the reproductive years. Int J Gynaecol, Obstet; 113:3-13.

12. Caglar GS, Tasci Y, Kayikcioglu F, Haberal A (2008). Intravenous tranexamic acid use in myomectomy: a prospective randomized doubleblind placebo controlled study. Eur J Obstet Gynecol Reprod Biol; 137:227.

13. Zhao F, Jiao Y, Guo Z, et al. (2011). Evaluation of loop ligation of larger myoma pseudocapsule combined with vasopressin on laparoscopic myomectomy. Fertil Steril; 95:762.

14. Frederick J1, Fletcher H, Simeon D, et al., (1994). Intramyometrial vasopressin as a haemostatic agent during myomectomy; 101(5):435-7.

15. Hung MH, Wang YM, Chia YY, et al. (2006). Intramyometrial injection of vasopressin causes bradycardia and cardiac arrest--report of two cases. Acta Anaesthesiol Taiwan; 44:243.

16. Frishman G (2009). Vasopressin: if some is good, is more better? Obstet Gynecol; 113:476. 